\title{
Single Versus Repetitive Doses of Natural Surfactant as Treatment of Respiratory Distress Syndrome in Premature Lambs
}

\author{
FRANS J. WALTHER, CARLOS E. BLANCO, MIEKE HOUDIJK, AND EDOUARD M. BEVERS \\ Departments of Neonatology and Biochemistry, University of Limburg, Maastricht, The Netherlands
}

\begin{abstract}
After delivery by caesarean section at 117120 and 125-130 days gestational age, 20 lambs were supported with infant ventilators at an $\mathrm{FiO}_{2}$ of 1.0 . Throughout the experimental period the respiratory settings were held constant. All lambs were treated by tracheal instillation of $50 \mathrm{mg}$ natural sheep surfactant lipid/kg body weight at $1 \mathrm{~h}$ of age, after respiratory failure had been documented. All lambs responded with a decrease in $\mathrm{PaCO}_{2}$ and increases in $\mathrm{PaO}_{2}$ and $\mathrm{pH}$, but these responses were of greater magnitude with advancing gestational age. Without waiting for respiratory failure to reappear, repetitive doses of natural surfactant were administered and the effects studied. Retreatment by instillation of $12.5 \mathrm{mg}$ surfactant/ $\mathrm{kg}$ at $2,3,4,5$, and $6 \mathrm{~h}$ of age was ineffective at 117-120 days gestational age, but sustained the initial response to the bolus of $50 \mathrm{mg}$ surfactant/kg at 125-130 days gestational age. This indicates that retreatment with natural surfactant should be started before the reappearance of respiratory failure in order to be effective, and that the response to retreatment with small, repetitive doses of surfactant is dependent on gestational age. (Pediatr Res 19: 224-227, 1985)
\end{abstract}

\section{Abbreviations}

GA, gestational age

RDS, respiratory distress syndrome

The RDS of the premature neonate is considered to be primarily due to surfactant deficiency (2). Endotracheal instillation of a bolus of natural surfactant in studies on premature animals $(1,4-6,10-17,19,22)$ and man $(7,8,23)$ produces a prompt improvement of pulmonary gas exchange and lung compliance, decreases lung injury, and increases survival time. In premature lambs at 120-130 days GA, the effect of a single dose of natural surfactant lasts for about $8 \mathrm{~h}$ if administered at birth but only about $3 \mathrm{~h}$ if administered soon after the establishment of respiratory failure (14). Retreatment after the reoccurrence of respiratory failure was successful in only $40 \%$ of the animals (14). This observation suggests that a second instillation of surfactant has a favorable effect, but this is probably limited by the presence of respiratory failure. The purpose of this investigation is to determine whether endotracheal instillation of small repetitive doses of natural surfactant sustains the effect of a bolus of surfactant administered to premature lambs in respiratory failure.

Received April 25, 1984; accepted July 13, 1984

Reprint requests: Dr. Frans J. Walther, Department of Neonatology, St. Annadal Hospital, P.O. Box 1918, 6201 Bx Maastricht, The Netherlands.

\section{MATERIALS AND METHODS}

Animals. Twenty premature lambs of known gestational ages were delivered by caesarean section of yearling ewes of the Texel breed (weight $41.2 \pm 1.2 \mathrm{~kg}$ ). The ewes were premedicated intravenously with atropine and $20 \mathrm{mg}$ xylazin hydrochloride (Rompun) and received local anesthesia. A hysterotomy was performed and the lambs were separated from the placenta and quickly weighed. Following intraperitoneal administration of 10 $\mathrm{mg} / \mathrm{kg}$ of pentobarbital sodium a midtracheal tracheotomy was done and an uncuffed endotracheal tube (i.d. $4.5-5 \mathrm{~mm}$ ) inserted and tied into the trachea. The lambs were then paralyzed with pancuronium bromide $(0.2 \mathrm{mg} / \mathrm{kg} /$ dose iv $)$. Both pentobarbital and pancuronium were repeated every $4 \mathrm{~h}$. The lambs were ventilated from birth with constant flow, time-cycled, pressurelimited ventilators (Amsterdam Infant Ventilator, MK 2) delivering humidified and warmed $100 \%$ oxygen. No tubes were inserted to prevent pneumothorax. The ventilator settings were held constant throughout the experimental period at an $\mathrm{FiO}_{2}$ of 1.0 , a rate of $30-40$ breaths/min, inspiratory time of $1 \mathrm{~s}$, peak inspiratory pressure of $25-30 \mathrm{~cm} \mathrm{H}_{2} \mathrm{O}$, and positive end expiratory pressure of $3 \mathrm{~cm} \mathrm{H} \mathrm{H}_{2} \mathrm{O}$. The lambs were dried and placed on a heating blanket under an infant radiant heater (Air Shields) and supplemental heat lamps. Core temperature was monitored with a rectal temperature probe and, after a short period of initial fall in temperature, maintained at $38-39^{\circ} \mathrm{C}$. Arterial blood gases and $\mathrm{pH}$ were taken every $15 \mathrm{~min}$ and measured with an AVL940 blood gas instrument. A 5 French polyethylene catheter was placed in the distal aorta via the right femoral artery and was used for continuous recording of blood pressure. Airway pressure was recorded continuously from a tracheal catheter in the proximal end of the endotracheal tube. In order to maintain glucose levels, $10 \%$ glucose was infused at a rate of $100 \mathrm{ml} / \mathrm{kg} / 24 \mathrm{~h}$ through a 3.5 French polyethylene catheter introduced into the inferior caval vein via the right femoral vein. After caesarean section maternal blood was drawn in heparinized syringes to transfuse the lambs for correction of hypotension soon after delivery or for blood replacement during the study period. No bicarbonate therapy was used to correct metabolic acidosis when it occurred in the lambs.

Natural surfactant. The surfactant was recovered by lung lavage of healthy adult sheep at a slaughterhouse. The procedure described by Jobe et al. (14) was followed with two modifications. Before the three-step centrifugation was performed, the lavage fluid was centrifuged at $200 \times g$ at $2^{\circ} \mathrm{C}$ for $20 \mathrm{~min}$ to remove tracheal debris and blood cells. Second, the last centrifugation step was repeated two times after resuspension of the resulting pellets in saline. Lipids were extracted according to the procedure of Bligh and Dyer (3). Phospholipid analysis was carried out by two-dimensional thin-layer chromatography followed by phosphorus determination of the isolated spots (24). Protein was measured using bovine serum albumin as standard (18). 
The necessary amount of surfactant was recovered in five batches (total $10.1 \mathrm{~g}$ ), with a maximum of about $300 \mathrm{mg}$ collected from each adult sheep. The phospholipid composition of each batch was identical; phosphatidylcholine comprised $76 \%$ of the total phospholipid (Table 1). The phosphatidylcholine to protein ratio was $22.62 \pm 6.42 \mu \mathrm{mol} / \mathrm{mg}$, indicating that very little protein was present.

Experimental protocol. One hour after birth all lambs were treated via tracheal instillation with an initial dose of $50 \mathrm{mg}$ natural sheep lipid/ $\mathrm{kg}$ body weight in a suspension of $18 \mathrm{mg} / \mathrm{ml}$. At treatment all lambs were in respiratory failure as defined for elevated $\mathrm{PaCO}_{2}$ levels and low $\mathrm{pH}$ values on at least two samples. The lambs were temporarily disconnected from the ventilator and the surfactant suspension at $37^{\circ} \mathrm{C}$ was instilled into the lungs over $20 \mathrm{~s}$. The lambs were then changed in position and hand ventilated for $30 \mathrm{~s}$ with an $\mathrm{FiO}_{2}$ of 0.21 and a peak inspiratory pressure of $25 \mathrm{~cm} \mathrm{H}_{2} \mathrm{O}$ to achieve as uniform a distribution of the suspension as possible. Thereafter the lambs were connected to the ventilator with no changes in the settings.

A total of 20 premature lambs were studied in three assigned groups. Group A consisted of six lambs at 117-120 days GA who received $50 \mathrm{mg}$ surfactant lipid/ $\mathrm{kg}$ body weight at $1 \mathrm{~h}$ of age, followed by hourly doses of $12.5 \mathrm{mg}$ surfactant lipid/ $\mathrm{kg}$ at $2,3,4,5$, and 6 h of age. Group B consisted of six lambs at $125-$ 130 days $\mathrm{GA}$ who received $50 \mathrm{mg}$ surfactant lipid $/ \mathrm{kg}$ body weight at $1 \mathrm{~h}$ of age, but no repetitive doses. Group $\mathrm{C}$ consisted of eight animals at 125-130 days GA treated as those in group A. Each lamb at 125-130 days GA was assigned on a random basis to group B or C. The lambs were sacrificed by iv administration of $300 \mathrm{mg}$ pentobarbital sodium $8 \mathrm{~h}$ after the initial dose of surfactant or after respiratory failure had reappeared $(\mathrm{pH}<7.00$ and $\mathrm{PaCO}_{2}>75 \mathrm{~mm} \mathrm{Hg}$ ).

All values are expressed as the mean \pm SEM. Statisical comparisons between groups of lambs were made using Student's two-tailed $t$ test.

Table 1. Phospholipid composition of natural surfactant in five batches

\begin{tabular}{lc}
\multicolumn{1}{c}{$\begin{array}{c}\text { Phospholipids } \\
\text { (\% composition) }\end{array}$} & $\begin{array}{c}\text { Natural surfactant } \\
(n=5)\end{array}$ \\
\hline Phosphatidylcholine & $76.02 \pm 0.62$ \\
Phosphatidylglycerol & $12.12 \pm 0.20$ \\
Phosphatidylethanolamine & $4.98 \pm 0.23$ \\
Sphingomyelin & $2.52 \pm 0.18$ \\
Phosphatidylserine & $0.94 \pm 0.09$ \\
Phosphatidylinositol & $0.96 \pm 0.07$ \\
Lyso-phosphatidylcholine & $0.90 \pm 0.09$ \\
Unidentified & $1.30 \pm 0.54$ \\
$\mu$ mol Phosphatidylcholine/mg protein & $22.42 \pm 6.42$ \\
\hline
\end{tabular}

\section{RESULTS}

Table 2 shows the gestational age; birth weight; age at first dose of surfactant; amounts of natural surfactant instilled; pretreatment values of $\mathrm{PaO}_{2}, \mathrm{PaCO}_{2}$, and $\mathrm{pH}$; mean arterial pressure; and peak inspiratory pressure. Soon after birth severe respiratory failure developed in all lambs despite high peak inspiratory pressures. The mean $\mathrm{PaO}_{2}, \mathrm{PaCO}_{2}$, and $\mathrm{pH}$ at the time of treatment were comparable. All lambs were normotensive and not tachycardic. The period from birth to initial treatment was similar for all lambs.

After the first dose of surfactant, the 117-120 days GA lambs of group $\mathrm{A}$ exhibited a prompt increase in mean $\mathrm{PaO}_{2}$ from 73 \pm 19 to $208 \pm 38 \mathrm{~mm} \mathrm{Hg}$. The mean $\mathrm{PaCO}_{2}$ decreased from 140 \pm 30 to $48 \pm 3 \mathrm{~mm} \mathrm{Hg} 1 \frac{1}{2} \mathrm{~h}$ after the first dose of surfactant and the $\mathrm{pH}$ values reflected this fall. After the initial response the lambs quickly deteriorated and were in respiratory failure at $3 \mathrm{~h}$ of age despite hourly doses of $12.5 \mathrm{mg}$ surfactant lipid $/ \mathrm{kg}$ (Fig. 1). $\mathrm{PaO}_{2}$ values dropped before the $\mathrm{PaCO}_{2}$ started to rise. The 125-130 days GA lambs of group $B$ showed a rise in mean $\mathrm{PaO}_{2}$ from $50 \pm 10$ to $240 \pm 27 \mathrm{~mm} \mathrm{Hg}$ after a single dose treatment. The mean $\mathrm{PaCO}_{2}$ dropped from $98 \pm 23$ to $27 \pm 3$ $\mathrm{mm} \mathrm{Hg}$ and the $\mathrm{pH}$ increased from $7.02 \pm 0.06$ to $7.37 \pm 0.04$ $1 \frac{1}{2} \mathrm{~h}$ after treatment. The duration of effect in group B was about $4 \frac{1}{2} \mathrm{~h}$ (Fig. 1). The $125-130$ days GA lambs in group $C$ had an initial response to the first dose of surfactant similar to that of group $\mathrm{B}: \mathrm{PaO}_{2}$ rose from $77 \pm 13$ to $294 \pm 24 \mathrm{~mm} \mathrm{Hg}$, $\mathrm{PaCO}_{2}$ dropped from $80 \pm 10$ to $33 \pm 5 \mathrm{~mm} \mathrm{Hg}$, and $\mathrm{pH}$ rose from $7.10 \pm 0.03$ to $7.37 \pm 0.051 \frac{1}{2} \mathrm{~h}$ after the first dose (Fig. 1). The administration of repetitive doses of $12.5 \mathrm{mg}$ surfactant/ $\mathrm{kg}$ to these lambs every hour through the 6th $\mathrm{h}$ after birth maintained a mean $\mathrm{PaO}_{2}$ above $200 \mathrm{~mm} \mathrm{Hg}$ at $9 \mathrm{~h}$ of age (Fig. 1).

The mean period from initial surfactant instillation to recurrence of hypoxia (defined by $\mathrm{a}^{\mathrm{PaO}_{2}}$ below $75 \mathrm{~mm} \mathrm{Hg}$ ) was 2.0 $\pm 0.2 \mathrm{~h}$ in group A, $4.0 \pm 0.5 \mathrm{~h}$ in group $\mathrm{B}$, and a minimum of $6.9 \pm 0.4 \mathrm{~h}$ in group $\mathrm{C}$. These differences are statistically significant $(p<0.001)$. Four of the eight lambs in group $C$ presented high $\mathrm{PaO}_{2}$ levels and normocapnia until sacrifice $8 \mathrm{~h}$ after the instillation of surfactant. The mean $\mathrm{PaO}_{2}$ values reached at peak response were higher in the lambs at 125-130 days GA than at $117-120$ days $\mathrm{GA}(0.05<p<0.10)$. Pneumothorax occurred in $50 \%$ of the lambs in each group, usually after the reappearance of respiratory failure. In one lamb from group A and in two lambs from group $\mathrm{C}$, sudden deterioration due to pneumothorax led to persistent hypoxia.

\section{DISCUSSION}

Tracheal instillation of a bolus of natural surfactant improves pulmonary gas exchange in premature animals and infants (1, $4-9,11-17,19,22,23)$, indicating that it can be delivered in an active form to the alveoli. Fifty $\mathrm{mg}$ surfactant lipid/kg body

Table 2. Characteristics of three groups of lambs

\begin{tabular}{|c|c|c|c|c|}
\hline : & $\begin{array}{c}\text { Group A, } \\
\text { repetitive } \\
\text { dose treatment }\end{array}$ & $\begin{array}{c}\text { Group B, } \\
\text { single dose } \\
\text { treatment }\end{array}$ & $\begin{array}{c}\text { Group C, } \\
\text { repetitive } \\
\text { dose treatment }\end{array}$ & $p$ \\
\hline No. of lambs & 6 & 6 & 8 & $<0.001^{*}$ \\
\hline Gestational age (days) & $117.8 \pm 0.5$ & $127.7 \pm 0.8$ & $127.5 \pm 0.9$ & $<0.001^{*}$ \\
\hline $\mathrm{Wt}(\mathrm{kg})$ & $2.3 \pm 0.1$ & $3.1 \pm 0.2$ & $3.0 \pm 0.2$ & NS† \\
\hline Age at treatment with surfactant $(\mathrm{h})$ & $1.03 \pm 0.06$ & $1.01 \pm 0.04$ & $1.14 \pm 0.06$ & NS \\
\hline Initial dose of surfactant $(\mathrm{mg} / \mathrm{kg})$ & $48 \pm 3$ & $50 \pm 1$ & $53 \pm 4$ & NS \\
\hline $\mathrm{pH}$ before treatment & $6.97 \pm 0.07$ & $7.02 \pm 0.06$ & $7.10 \pm 0.03$ & NS \\
\hline $\mathrm{PaO}_{2}$ before treatment $(\mathrm{mm} \mathrm{Hg})$ & $73 \pm 19$ & $50 \pm 10$ & $77 \pm 13$ & NS \\
\hline $\mathrm{PaCO}_{2}$ before treatment $(\mathrm{mm} \mathrm{Hg})$ & $140 \pm 30$ & $98 \pm 23$ & $80 \pm 10$ & NS \\
\hline Mean arterial pressure before treatment $(\mathrm{mm} \mathrm{Hg})$ & $48 \pm 3$ & $56 \pm 3$ & $54 \pm 3$ & NS \\
\hline Peak inspiratory pressure before treatment $\left(\mathrm{cm} \mathrm{H}_{2} \mathrm{O}\right)$ & $31 \pm 2$ & $29 \pm 1$ & $28 \pm 1$ & NS \\
\hline
\end{tabular}

*A $v s$ B and C.

$\dagger$ Not significant, $p>0.05$. 


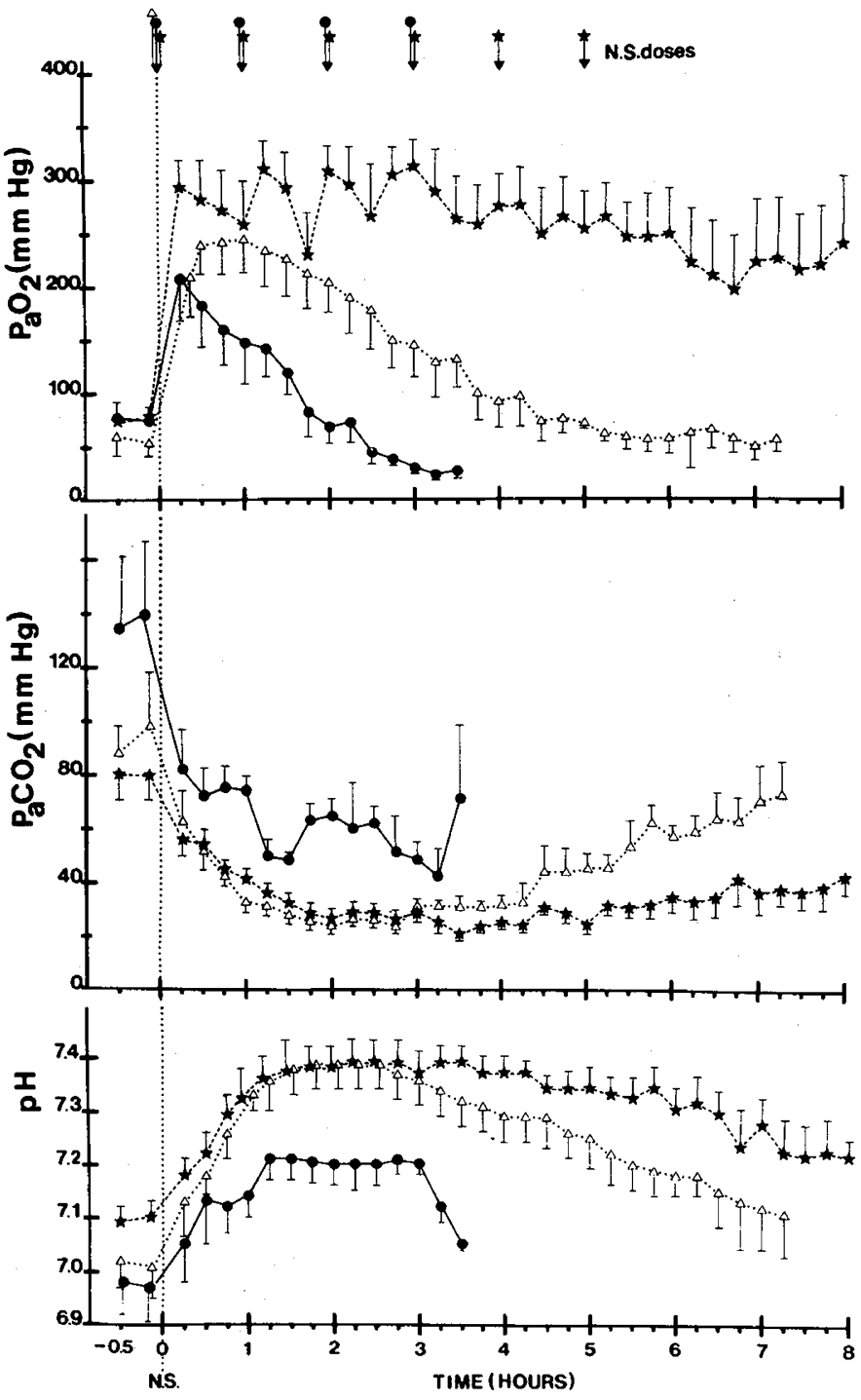

Fig. 1. Sequential $\mathrm{PaO}_{2}$ (in $\mathrm{mm} \mathrm{Hg}$ ), $\mathrm{PaCO}_{2}$ (in $\mathrm{mm} \mathrm{Hg}$ ) and $\mathrm{pH}$ values. Group A (117-120 days $\mathrm{GA})$ is represented by $\bullet$, group B (125130 days GA) by $\Delta$, and group $C(125-130$ days GA) by $\star$. All lambs were treated with $50 \mathrm{mg}$ surfactant lipid/ $\mathrm{kg}$ (NS) at zero time. Repetitive doses are shown at the top (NS doses). All values are expressed as mean $\pm \mathrm{SE}$.

weight improves clinical status as well as the pressure volume and surface balance characteristics of the lungs (10). However, only $19 \mathrm{mg}$ surfactant lipid/ $\mathrm{kg}$ seems to produce improvement in the clinical parameters (10). In this study we affirmed the positive effects of tracheal instillation of a bolus of $50 \mathrm{mg}$ natural surfactant lipid $/ \mathrm{kg}$ in lambs at gestational ages of 117-120 and 125-130 days with established respiratory failure soon after birth. Comparison of the responses in these two gestational age periods demonstrates that the response increases with advancing gestational age.

Tracheal instillation of a bolus of surfactant is effective for a limited period only (14) and does not change endogeneous synthetic and secretory rates (20). As RDS in premature infants starts to improve after about $48 \mathrm{~h}$ of age due to de novo synthesis of surfactant, we tried to maintain the effects of the first dose of surfactant by repetitive administrations of smaller doses. Our results show that at 125-130 days gestational age the initial response to tracheal instillation of $50 \mathrm{mg}$ surfactant $/ \mathrm{kg}$ can be sustained by reinstillation of repetitive doses of $12.5 \mathrm{mg}$ surfactant $/ \mathrm{kg}$ at 1-h intervals. This positive effect of repetitive doses was not seen at 117-120 days gestational age and may thus be dependent on gestational age. At 125-130 days gestational age, the quantities used are probably sufficient to cover the loss of surfactant in the lungs due to clearance from the airways and the presence of surfactant inhibitors which may influence the activity of exogeneous surfactant $(11,14)$. However, the repetitive doses of $12.5 \mathrm{mg}$ surfactant lipid/ $\mathrm{kg}$ (one-fourth of the initial dose) were estimated on the basis of the reported 2- to 4-h duration of response to a bolus of $50 \mathrm{mg}$ surfactant $/ \mathrm{kg}$ in lambs at $120-130$ days gestational age with established $\operatorname{RDS}(10,13,14)$. It is possible that smaller repetitive dose could be used to obtain similar effects.

In the study of surfactant instillation, the method of administration alone may have beneficial effects (9). Repetitive doses of saline with manual ventilation were not administered to control lambs in this study. However, by performing manual ventilation with peak inspiratory pressures and $\mathrm{FiO}_{2}$ well below the ventilator settings, we probably avoided any positive effect of method of administration.

It remains speculative whether it is necessary to administer a large bolus of surfactant when initial treatment is followed by repetitive doses. It could be the case that the effects of a smaller initial dose can be sustained by repetitive doses. In neonates at 27-30 wk gestational age, RDS stabilizes for 8-15 h after the instillation of a bolus of $60 \mathrm{mg}$ human surfactant $/ \mathrm{kg}(8)$. Retreatment of these neonates with smaller doses of surfactant at 4- or 6-h intervals might prevent sudden changes in their clinical condition associated with complications such as patent ductus arteriosus (7), air leaks, and intraventricular hemorrhage (21).

Acknowledgments. We wish to thank Dr. A. v. d. Bogaard and the biotechnical staff, and Dr. F. Bonke and the technicians of the Department of Physiology for their cooperation and support.

\section{REFERENCES}

1. Adams FH, Towers B, Osher AB, Ikegami M, Fujiwara T, Nozaki M 1978 Effects of tracheal instillation of natural surfactant in premature lambs. I. Clinical and autopsy findings. Pediatr Res 12:841

2. Avery ME, Mead J 1959 Surface properties in relation to atelectasis and hyaline membrane disease. Am J Dis Child 97:517

3. Bligh EG, Dyer WJ 1959 A rapid method of total lipid extraction and purification. Can J Biochem Physiol 37:911

4. Egan EA, Notter RH, Kwong MS, Shapiro DL 1983 Natural and artificial lung surfactant replacement therapy in premature lambs. J Appl Physiol 55:875

5. Enhorning G, Hill D, Sherwood G, Cutz E, Robertson, B, Bryan C 1978 Improved ventilation of prematurely delivered primates following tracheal deposition of surfactant. Am J Obstet Gynecol 132:529

6. Enhorning G, Robertson B 1972 Lung expansion in the premature rabbit fetus after tracheal deposition of surfactant. Pediatrics 50:58

7. Fujiwara T, Maeta H, Chida S, Morita T, Watabe Y, Abe T 1980 Artificial surfactant therapy in hyaline membrane disease. Lancet 1:55

8. Hallman M, Merritt TA, Schneider H, Epstein BL, Mannino F, Edwards DK Gluck L 1983 Isolation of human surfactant from amniotic fluid and a pilot study of its efficacy in respiratory distress syndrome. Pediatrics 71:473

9. Hurt H, Kattwinkel J, Roth S 1983 Artificial surfactant treatment in lambs with severe respiratory distress syndrome: a controlled study. J Pediatr $102: 450$

10. Ikegami M, Adams FH, Towers B, Osher AB 1980 The quantity of natural surfactant necessary to prevent the respiratory distress syndrome in premature lambs. Pediatr Res 14:1082

11. Ikegami M, Jobe A, Glatz T 1981 Surface activity following natural surfactant treatment in premature lambs. J Appl Physiol 51:306

12. Ikegami M, Jobe A, Jacobs H, Jones SJ 1981 Sequential treatments of premature lambs with an artificial surfactant and natural surfactant. J Clin Invest 68:491

13. Jacobs H, Jobe A, Ikegami M, Glatz T, Jones SJ, Barajas L 1982 Premature lambs rescured from respiratory failure with natural surfactant. Clinical and biophysical correlates. Pediatr Res 16:424

14. Jobe A, Ikegami M, Glatz T, Yoshida Y, Diakomanolis E, Padbury J 1981 Duration and characteristics of treatment of premature lambs with natural surfactant. J Clin Invest 67:370

15. Jobe A, Ikegami M, Glatz T, Yoshida Y, Diakonanolis E, and Padbury J 1983 Saturated phosphatidylcholine secretion and the effect of natural surfactant on premature and term lambs ventilated for 2 days. Exp Lung Res 4:259

16. Jobe A, Jacobs H, Ikegami M, Jones S 1983 Cardiovascular effects of surfactant suspensions given by tracheal instillation to premature lambs. Pediatr Res $17: 444$

17. Lachmann B, Grossmann G, Nilsson R, Robertson B 1981 Effect of supplementary surfactant on in vivo lung mechanics in the premature rabbit neonate. Eur J Pediatr 136:173 
18. Lowry OH, Rosebrough NJ, Farr AL, Randall RJ 1951 Protein measurements with the Folin phenol agent. J Biol Chem 193:265

19. Metcalfe IL, Pototschnik R, Burgoyne R, Enhorning G 1982 Lung expansion and survival in rabbit neonates treated with surfactant extract. J Appl Physiol 53:838

20. Oguchi K, Ikegami M, Jacobs HC, Jobe AH 1984 Clearance of large amounts of natural surfactant and dipalmitoylphosphatidylcholine from the lungs of 3-day-old rabbits following tracheal injection. Pediatr Res 18:337A

21. Perlman JM, McMenamin JB, Volpe JJ 1983 Fluctuating cerebral bloodflow velocity in respiratory-distress syndrome. Relation to the development of intraventricular hemorrhage. N Engl J Med 309:204

22. Robertson B 1980 Surfactant substitution; experimental models and clinical applications. Lung 158:57

23. Smyth JA, Metcalfe IL, Duffty P, Possmayr F, Bryan MH, Enhorning G 1983 Hyaline membrane disease treated with bovine surfactant. Pediatrics 71:913

24. Verkley AJ, Zwaal RFA, Roelofsen B, Comfurius P, Kastelijn D, and Van Deenen LLM 1973 The asymmetric distribution of phospholipids in the human red cell membrane. Biochim Biophys Acta 233:178

\title{
Correlation between Fetal and Maternal Serum Bile Acid Concentrations
}

\author{
CARLA COLOMBO, ALDO RODA, ENRICO RODA, MAURO BUSCAGLIA, \\ CARLO ALBERTO DELL'AGNOLA, PAOLA FILIPPETTI, MARIANGELA RONCHI, AND \\ FABIO SERENI
}

Department of Pediatrics and Pediatric Surgery [C.C., C.A.D., M.R., F.S.], and Department of Obstetrics and Gynecology [M.B.], University of Milan, and Istituto di Scienze Chimiche and Clinica Medica III [A.R., E.R., P.F.], University of Bologna, Italy

\begin{abstract}
Serum concentrations of different bile acids (BA) were determined by radioimmunoassay in 56 human fetuses and mothers. Serum was obtained immediately after legal abortion, performed between the 14th and the 21 st wk of gestation. Conjugated cholic (CCA) and chenodeoxycholic acid (CCDCA) concentrations were determined in 33 cases, conjugated lithocholic (CLCA) and deoxycholic acid (CDCA) in 20, and sulfolithocholyglycine (SLCG) in 15. In fetal blood, mean concentrations of CCA $(0.80 \pm 0.40 \mu \mathrm{mol} / \mathrm{liter})$, CCDCA (4.50 $\pm 2.70 \mu \mathrm{mol} / \mathrm{liter})$, and CLCA (1.70 $\pm 1.04 \mu \mathrm{mol} / \mathrm{liter})$ were significantly higher than those in the mother (CCA $0.34 \pm 0.17 \mu \mathrm{mol} /$ liter; CCDCA $0.79 \pm 0.34 \mu \mathrm{mol} / \mathrm{liter}$ CLCA: $0.70 \pm 0.30$ $\mu \mathrm{mol} / \mathrm{liter} ; \boldsymbol{p}<0.001)$; fetal serum levels of CDCA (0.46 $\pm 0.32 \mu \mathrm{mol} /$ liter $)$ and SLCG $(0.15 \pm 0.09 \mu \mathrm{mol} /$ liter $)$ were lower than in the mothers (CDCA $1.20 \pm 0.80 \mu \mathrm{mol} / \mathrm{liter}$, $p<0.001$; SLCG $0.40 \pm 0.30 \mu \mathrm{mol} / \mathrm{liter}, \mathrm{p}<0.01)$. There was no correlation between levels of $\mathrm{BA}$ and gestational age. Serum total protein and albumin concentrations were both reduced in $\mathbf{1 0}$ fetuses as compared with the mothers. These data support the concept of a state of physiologic cholestasis during development and suggest that placental transfer of primary BA occurs mostly in the fetal to maternal direction. This transfer could be facilitated by the reduced fetal plasma albumin concentration, since $\mathrm{BA}$ in free solution diffuse more easily through the placenta. There is evidence of lithocholic acid synthesis in the fetal liver, while deoxycholic acid appears to be mostly of ma-
\end{abstract}

Received April 5, 1984; accepted August 8, 1984

Correspondence Dr. Carla Colombo, Clinica Pediatrica II, University of Milan, School of Medicine, Via Commenda 9, 20122 Milan, Italy.

This study was presented in part at the annual Meeting of the American Pediatric Society and Society for Pediatric Research, San Francisco, May 1984, and published in abstract form (Pediatr Res 18:193A, 1984). ternal origin. Finally, sulfation of BA is poorly developed at this age of gestation. (Pediatr Res 19: 227-231, 1985)

Abbreviations

BA, bile acids

CCA, conjugated cholic acid

CCDCA, conjugated chenodeoxycholic acid

CDCA, conjugated deoxycholic acid

CLCA, conjugated lithocholic acid

SLCG, conjugated sulfolithocholic acid

We recently reported that the fasting serum concentrations of the two primary BA conjugates, CCA and CCDCA, are significantly elevated during the first few months of life (3). However, during the ist yr of age, concentrations decrease to values similar to those of adults. This state of hypercholanemia, reflecting an immaturity of the enterohepatic circulation, has since been corroborated by other investigators using similar radioimmunoassays $(4,25,27)$, and "physiologic cholestasis" is now recognized as a normal developmental condition. The factors responsible for physiologic cholestasis have not yet been completely defined in the human infant; data obtained in animal models have documented the immaturity of several of the processes involved in the enterohepatic circulation of BA (hepatic uptake, conjugation, excretion, and intestinal absorption) $(5,10,23,24,26)$. However, the presence of marked species differences, as has been well demonstrated for other fetal hepatic excretory mechanisms, makes it difficult to extrapolate these data to the human infant. Data concerning metabolism and placental transfer of BA in the human fetus are extremely limited.

The aim of this study was to determine the relationship between fetal and maternal serum BA concentration and compo- 